\title{
ÖLÜM VE ÖLÜMCÜL HASTALIK
}

\section{UIgen OKYAYUZ*}

Hastalık, bıreyın o gune kadar getırdığı tum yaşam dengelerı ıçın bır tehdıt oluşturan, stress yaratan bır yaşam olayı, bır engellenmedır Boyle bır durum bıreyı, sahıp ołduğu psıkolołık, sosyal ve ekonomık vb her turiu uyum sağlayıcı donanımını kullanarak uyum yapmaya zorlar (Lazarus \& Launıer 1978) Bu tehdit bıreyın olağan yaşamını sadece bırkaç gunluk bozma anlamında etkılemekten, onu olum gibı, yaşamın en kaçınıımaz gerçeğı ıle yuzyuze getirebılen bir spektrumun herhangı bir nokta. sinda yer alabilır

$\bigoplus_{\substack{\text { Kısa surelı } \\ \text { geçıci hastalık durumu }}}^{\text {Hastalık }}$

Bu şu demektır, bır bıçımde o gune kadar getırtlen, gunluk yaşamı surdurmekte kullanılan tum mekanızmalar, geleceğe yonelık beklentıler, planlar. kısacası tum dengeler en azindan sarsilmak, bozulmak ya da yıtırılmek gibı bır tehdıtle karşı karşıyadır Bu tehdıt, bıreyın olağan yaşamından belkı sadece bellı bır mıktar ekonomık gucu, Işı yitırmek gibı bır durum olabıleceğı gıbı, herhangı bır organı. nı ya da ışlevını, ya da tumuyle yaşamını yıtırmek yanı olmekle yuzyuze gelmek anlamını da taşıyabıirr Kayıp olgusu ve bununla tlgıl! olarak yaşanan yas surecı bugun pek çok patolojık davranışın açıkianmasında onemle uzerınde durulan bir yaklaşımdir

Doç Dr AU Tıp Fakulıesı Psikıyatrı ABD Klınık Psıkolojı Ogretım Uyesı

\section{KAYIP NEDIR?}

Bıreyın kaybı derken onun yaşamında kendısı ıçın onemiı olan nesnelerın-kışlier, organlar, ışlevler, hayvanlar vb- yıtırilmesı anlaşılmalıdır Bır önek vermek gerekırse kronık bır kalp hastalıgında bıreyın o gune kadar surdurduğu gunluk etkınıklerını, olağan duzeyınden daha aza ındırgemesının de onun ıçın bur yitım olduğu soylenebılır $8 u$ tum hastalıklara yayılabılır Boyle bır yıtım karşısında bırey yas tutar Bu çok doğal, beklendık bır duygulanım surecidır Bunun yaşanılmaması, bastırıması, yok sayılması gıbı tepkıler yasın kronıkleşerek patolojık bir hale gelmesine ve depresyon, psıkosomatı hastalıklar, patolołık yas gıbı klınık tabloların oluş. masına yol açar (Volkan 1985, s 271) Bu konuyla ilgılenen araştırmacılardan Kubler-Ross (1969) depresyonun, yıtırıien etkınlıkler ıçın tutulan yasın ónemiı bır parçası olduğunu da vurgulamaktadır

Bır bıreyın yaşamında rastlayacağı en kaçınılamaz kayıp olgusu ise olumdur Insanoğlunun bugunku algı sınırları ıçınde bılebıldığı tek mutlak gerçek ve en buyuk bilınmeyen olan olum karşısında bırey değışık savunmalar gelıştırır Insanlar yaşa. mın bu acı veren gerçeğını anlamak ıçın yuzyıllardir uzerinde duşunup durmuşlardır Hesıodos Thegonıa'da ılk ogelerın doğuş sureçını şoyle anlatır, "Kaos'tan once Gaia (Toprak), sonra Erebos'la, Nyks yanı yeraltı ve yeryuzu karanlıkları çıkar Sonra Nyks kendi kendine uretmeye koyulur, ortaya çıkardığı varlıklar kotuluğu, açlığı, yıkım ve olumu stmgeleyen karanlık guçlerdır Uç olum tanIIsı Moros, Ker ve Thanatos, Hypnos (uyku) ve 
Oneıros (duş) " (Alıntı kaynak, Erhat 1978, s 280) Bu tanrıların ıçınde Thanatos, gece anlamına gelen Nyks'ın çocuğu, uykumun kardeşıdır "Bırbirlerinden ayrimayan Hypnos'la Thanatos yeraltında Tartaros'un derınlıklerınde otururlar" (A g e , s 362) Tartaros " oylesine derındir kı bır yılda varılamaz dıbıne" (A g e , s 358) Tek Tanrilt dinsel oğretılerde yer alan yaşamın olumden sonra da sureceğı gıbı ınançların yanısıra olumu bır şeytan, bır canavar halınde duşunerek onu kışleştırme çabaları da bir bıçınde bızı gerçekle yuzyuze gelmekten alıkoyar Boylesı tutumlar gerçeğı tum çıplakıı̆ıyla yaşamaktan daha az korkutucudur Gunluk yaşamımızda da yetışkın ınsanlar olarak bızler olum kavramını daha oiumlu hale dơnuşturmeye çalışır, oien yakınlarımız ıçın goç ettı, Tanrıyia buluştu, ebedı huzura erdı vb ıfadeler kullanmayı yeğlerız

Olumu nasıl yaşadığınızı, algıladığınızı lutten duşunun Gózledığım kadarıyla tedavı kurumların$\mathrm{da}$, tedavı ekıbı uyelerı olen bır hasta ıçı " $X$ bey oldu" demek yerine, "X numara ex oldu", ya da "Hasta masada kaybedild" demeyı yeğlıyorlar Butun bunlar olum kavramının sımgeledığ kayıp olgusuyla bızlen doğrudan yuzyuze gelmekten alıkoyan tutumlardır Içınızde bazılarınız "Ben olumu yadsımıyorum” diyebilı Yalom'a gore "Bız olum hakkında çoğunlukla olguları konuşuyoruz Onun bızde yarattığı duyguları, dehşetı değı" (Yalom 1989, s 5) Yalom'a góre olum olgusunun kendisı yok edıcı ama olum uzerinde duşunebılmek, onunla ılgili duygularımızı farkedebılmek, paylaşabıimek, kişıyı zengınleştıren bır tutumdur

Bıreyın kayıpların en somutu olan olum olgusuna verdığı tepkı bıçımı, onun daha once yaşadığı dığer tamamianamamış -yaşayıp bıtırilememış. zorlanmış ya da aceleye getırımış ayrımalarının (separation) artıklarım taşır Başka bı deyışle "olum bızım emosyonel yaşamımızı, kışısel acılarımızı bıçımlendıren koşullars, durumları açıklayan bır prototip olarak yaşanır" (Volkan 1993, s 4)

Kayıplar karşısında bıreyın yaşadığı yas tutma surecinde uç temel oğeyı her zaman gozonunde tutmak gerekir

1 Her kayıp, bıreyde kaçınımaz bır elem, acı surecı başlatır

\section{Her kayıp, geçmış kayıplanı tazeler}

3 Her kayıp, eğer doğru durust yaşanırsa psıkolojık buyume ve yenilenme ıçın bir araç olabıı ır (Volkan 1993, s 4)

Yınelemek gerekırse, her kayıp olgusunun bırey ıçın ne anlam ı́ade ettığının, O'nda hangı korkuları, tehıkelen ateşledığının, harekete geçırdığının ve hangı eskı acıları tazeledıgının her zaman gözōnunde tutulması gerekır Herbırımızın yaşam surecı de bu streslerle yuzyuze gelme becerilenmiz, kayıp karşısında gösterdığımız uyum ve bu kayıp olgusunu buyümek ıçın bır değışım aracı olarak nasıl kullanabıldığımıze bağlıdır

\section{ÖLUMCÚl HASTALIK TANISI ALAN BjREY NELER YAPAR?}

Boyle bır durumia karşılaşan bıreyın, sorunun ustesınden gelebılmek ıçın harcadığı çabaları genel olarak 5 grupta toplayabilınz

1 Bilgi edinme Hastalikla ligili bilgi edinme Boyle bır bilgılenme hem sorunun çozumune katkıda bulunur, hem de emosyonel yaşamın duzenlenmesıne, self-concept'i guçlendirerek, self-esteem'ın surdurulmesıne yardım eder Bırbırıyle çok ılışkılt olan bu Ikt kavramdan self-esteem kendilik değen, self-concept ise kışının kendısını nasıl tanıdığı, yorumladığ anlamını taşır Konuyla ılgısı nedenıyle self-concept'ın alt ogelerıne kısaca değınmekte yarar vardir

a Fizıksel self Bireyın kendı beden ımgesıdır Bu, bıreyın fızıksel gorunumunu ve ışlevselıı̆ını algılama bıçırmı ve değerlendırmesıdır Selfconcept in beden-ımgesı ogesı hastalık tarafindan onemli bır bıçımde etkılenır Bedenın sadece hastalanmış kısmı değıl, tum beden olumsuz bır bıçımde algilanır Yuzle ıgılı zedelenmelerde hastaların bu deḡışmış ımgelerını gerçek anlamda kabul edemeyebıldıklerı de ılerı surulmektedır Bunun nedenterı arasında yuzun, çoğunlukla kışılıkle -eş değermışcesıne- bırlıkte algılanması ve buradakı bır zedelenmenın kışılıktekı bır zedelenme olarak kabul edılme. si ve yuzdekı bozulmaların kolay maskelenememesı sayılabilır

b Başaran self (The Acheving self) Meslekı ve 
amator uğraşlar bıreyın self-esteem ve selfconceptının ơnemlı görunumlerıdır Pek çok ınsan ışınden ve karıyerınden bırıncıl doyum sağlar Hastalığın şıddetı selfın bu değerlı kısmı ıçın onemlı bır tehdit oluşturabilır

c Sosyal self Hastalığa yenıden uyum yapabilmenın ónemlı bır görunumu de sosyal selfı yenıden kurabılmektır Aıle ve arkadaşlarla olan etkıleşımler self-esteem'ın krıtık kaynağını oluşturabılırler

a Ozel self (The Private Self) Hastanın kımlığnın (amaçları, ısteklerı, hırsları vb) resıduel çekırdeğıdır Hastalığa uyum ıçın on kestırım değerı vardır (Taylor 1986, $\mathrm{s} 344$ )

2 Doğrudan eyleme gurme Hastalığın tedavısı ıçın uygun yerlere vb başvurmak bu çabalar çerçevesınde ele alınabilır Bireyler eylemde bulunabidıklerı durumlarda, kendılerınde kaygı yaratan ıçınde bulundukları ortama egemen olduklari, onu kontrol edebildiklen duygusunun oluşması onemidır Neden? Bu soruya yanıt verebilmek ıçın bıraz kontrol kavramı uzerinde durmak gerekır Kontrol gereksınımı ozellıkle bıreyın, uyum sağlayıcı açık bır yanıtının olmayacağı, kendısı ıçın tehdıt oluştu. ran bır durumla karşılaşması haıınde onem kazanır Insanlar hoş olmayan bır olayı bıtırmek ya da deģıştırmek gibı bır psıkolojk kontrol duygusuna sahıp olduklarında bu duygu onlara olayla daha başarılı bır şekılde başa çıkmak gucunu verır Psı. kolojık kontrol, daha once sozunu etığımız selfconcept ve self-esteem kavramları ıçı temeldır ve stress duygusunu azaltır Kontrolun yıtırıldığ duygusu bireyde depresyon, çaresizitk ve umitsizlik gıbı duygulara yol açar (Selıgman 1975) Kontrolun yitııımesı, bireylerın etkılenmeye olan duyarlııklarını arttırır ve onları sıkça, rastgele, ayrışmamış bır bıçımde bilgı aramaya goturur insanlar korktukları bır hastalık surecı yaşamak durumunda kaldıkların. da, leride olacak l.ontrol yıtımı duygusunu onceden yaşamaya başlayabıırier Bu, ozeltıkie surę̧ hakkinda gorece bilgilerının az olduğu durumlarda doğrudur Bu kışıter olayın olumsuz etkısınden kurtulmak ıçın yapabıleceklerı pek az şøyın olduğunu duşunurler Bu nedente de davranışçı, błlışsel vb kontrol temellı mudahalelerin bıreyı daha bilgilı ve sonuçta tedavılerını de daha etkılı kılması beklenebılır Bıreylerın yaşadıkları olayların kaynağının kendilennden ya da çevreden gelıp gelmedığıne olan inançları (Locus of control) bu mudahalelerin başarısında etkilıdır lçrel kontrol kaynağına sahıp olan kışıler kendilerını, yaşadıkları olayların kaynağ olarak görurler Bu kışılerın, hastalık gıbı hoş olmayan durumlar karşısında, bazı ozgul durumları değıştırme olanağı veren kontrol-temellı mudahale. lerden (Davranışçı-Bılışsel vb) daha çok yararlanabileceklerı beklenır Kontrol odağının dışarıda oldugu inancindakt bireyler ise sozu edilen mudahalelerden hoşlanmayabilıler Kısacası bu konuları daha cok hekıme birakabulurler Ancak bu kışılerın de bakımlarına ılışıın bılgılendırmeden aynı bıçımde yarar sağlayacakları ılerı surulmektedır (Taylor 1986, s 344)

3 Eylemın ketlenmesı Bırey ıçınde bulunduğu durumla başa çıkmakta kendısı ıçın tehlıkelı olabılecek, ımpulsıve, şaşırtıcı davranışlarda bulunabilır (Hekıme gıtmemek, lacı reddetmek gıbı)

4 Intrapsışık çabalar Intrapsışık çabalar bağlamında olumcul hastalarda yaşananlarla ılgılı olarak, once Yalom'un tanımladığı ıkı savunmadan sóz edılebilir (Yalom 1980) Yalom bu grup hastalarda ólum korkusunu bastırmakta yaygın ve guçlu bıçım. de kullanılan $\mathrm{kı}$ Inanç ya da sanrıdan sózeder Bunların ılkı, kışının ozel olması (personel specralness), diğerı ise bur kurtarıcı gelecek (ultımate rescuer) inançlaridir Ozel ofma, insan biyolojisinin ve kaderının olağan yasalarının otesınde, bıreyın kışsel dokumulmazliğ' (inviolable) ve incitilemez (invulnerable) olduğu inancıdır Ancak yaşamın her hangı bır yerınde cıddı bır hastalık, bır boşanma vb gıbı yaşam olayıyla karşılaştığımızda kendımızın ne denlı alelade, sıradan oldugumuz gozler onune serlıverır Kışısel dokunulmazlık ınancı bıreye kendı ıçınde gorece bır guvenlık duygusu sağlar Enınde sonunda bır kurtarıcı gelecek inancı ise bıze, dişarıdan bır guç tarafından gozetıldığımız, korunduğu muz duygusune verır Yalom bu tkı ınanç sıstemının ınsanın varoluş durumuna ters duşen bır dialektik oluşturduğunu ller surer Ona gore birey ya kahramanca bir attiłm, ya da ustun bir guç ıçın. de erıme yoluyta guvenlik arar Ozellikle bu Ikıncı ınancın hekım-hasta ılı̧kılerınde onemlı olçude etkı li olduğu ve hastanın beklentılerının bıçımlenmesın. de payı olduğu duşunulebilıt

Intrapsışık başa çıkma mekanızmalarını kanserı 
hastalarda tanımlayan bur diğer yazar Elizabeth Kubler-Ross'dur (1969)

a Yadsıma "Hayır, ben ólmem" (Yalom'un tanımiadığı bırıncı ınançla olan benzeriığıne dikkat edınız) Hastalığını oğrenen kışının bırkaç gun suren alışılmış tepkısıdır ve bıreye yuzyuze geldığı "gerçek"ten korunmak ıçın bır sığınak görevı yapar, yaşanan anksiyeteyı maskeler Kubler-Ross yadsimanin onemlı ve gereklı olduğunu belırtmektedır Hasta olumun kaçınıımazığının bılıncıne vardığında darbenin gucu azalmiştır Bu savunmanın primıtıf ve başarısız bır savunma olduğu da ılen surulmektedir (Taylor 1991)

$b$ Ofke llk bırkaç gunden sonra artık yapılaçak tedaviler, hastanın nerede tedavı olacağı ve kımın tarafından tedavı edıleceğı gıbı kararların alınması zorunluluğu ortaya çıkar Dr Kubler-Ross'a gore bu noktada ofke gelışır "Neden ben?" sorusu sorulur Başkaları sağ ve sağlıklı kalacakken kendısının oleceğı gerçeğı karşısında hasta ıçerter Bu kızgınlığında Tanrtyı hedef alır Çunku olum hukmunde O'nun zorlayıcı ve keyfine gore davrandığı duşunulur Ofkelı hasta, sağlıkı olan herhangı bır kışıye, orneğın hastane personelı, arle uyelerı ya da arkadaşlarına ofkesını yóneltebilır Ófke, aule ve arkadaşları ıçn başedılmesı guç durumlardan bırısıdır Aslında bu insanlar sağlıkı olmaları yuzunden hastanın ofkesılyle yuzyuze gelmektedırler

c Pazarigga gırme "Evet amal" Bu noktada hasta daha farklı stratejler ıçın ofkeyı bır yana bırakır lyı davranma karşıığında sağlıklı olma gıbı Bır başka deyışle hasta olum gerçeğını kabullenırse de daha uzun sure yaşamak ıçın pazarı̆ga gırer Bır hafta, bır ay ya da bır yıl daha yaşamak ıçın, ıyı bır ınsan olmaya ya da ıyı davranışlarda bulunmaya soz verır Taylor'a (1991) gore olume karşı ofke ve pazarlığın temelınde "sosyal değış-tokuş (takas)" ya da "eşıtlık" kavramları vardır Insanlar "dunyanın adıl' olduğuna ıışkın, çok derınlerde yerleşmış bır ınanca sahıptırler, "lyı şeyler ıylık yapanların, kotu şeyler de kotuluk yapanların başına gelır "Olumcul hastalıkta olduğu gıbı bır tehdıt ortaya çıktığında, bu durum sozu edilen bu doģal sıratanmayı bozar Buna uygun olarak da bireyin dunyanın adil olduğu duygusunu korumak ıçın sart ettığı çabalar, bu tehditle igilı clarak once ofke ve daha sonra da pazar. lık yoluyla bu "adaletı" tekrar kurmak uzere pazar- lık gınşımlerı bıçımınde surdurulur (Tayłor, 1991, s 415)

d Çơkuntu (Depresyon) Hastalığın adalet yasalarına hıç de uymadığı, harcanan çabaların durumu duzeltmeye yetmedığı farkedıldiğınde depres. yon yerleşır Bu aşamayı hastalığın seyn uzerınde "kontrolun yitırılmesı" bağlamında da anlayabłıırız Kubler-Ross bu çokuntu aşamasını "kedere hazırlanma" olarak tanımlar Bu aşamada hastalar kendı olumlennın yasını tutarlar Bu kederiı sureç ıkı aşamada gerçekleşır Kışı ónce geçmışte kaybettıklerıne, yapamadıklarına, hatalarına sơylenmeye başlar Ancak sonra kendisını gelecek olan olumune hazırlar Kubler-Ross, hastanın bu donemde buyuduğunu belıtmektedır Yıne Kubler-Ross, bu aşamada yaşanan depresyona mudahale edılmemesı, bunun yerıne en azından bır sure kendı akışına bı. rakılmasının uygun oldugunu tierı surmektedır Kuşkusuz, depresyonun gıderek kotuleştığı, sosyal uyaranlara yanıt alınamadığı, yemek yemenın reddedıldıgı vb durumlarda gereklı mudahaleler yapılmalıdır (Kubler-Ross, 1969)

e Kabullenme "Artık sonum çok yaklaştı Herşey tamam ${ }^{*}$ Kubler-Ross, bu aşamanın duygulardan yoksun olduğunu ve bunun gerçek bır zafer olduğunu ılerı surmektedır Bu aşamadakı hasta artık ofkelenmeyocek kadar zayıftır ve "olmek" kavramına da alışmıştır Hasta yorgun ve sakındır

Kısaca tanımlamaya çalıştığımız bu aşamalar kesin sintrlamalar olmamakla birlikte olumcul hastaları anlayabılmekte bize ónemlı bir rehberdır Kubler-Ross, bu evrelerde umutu onemlı ve sureklı bır etken olarak górmektedır Yenı bır ılaç, bır araştı mada son dakıkadakı bı başanı, yenı bır tedavı yontemı gıbı duşunceler hastanın son aylarına, haftalarına kadar koruduğu duşuncelerdendır Bu umut sadece ryleşme umudu değıldır Aynı zamanda olumu kabul ederek olme umududur Bu umut, hem olumu ve hem de olum kederin daha insancil ve anlamiı kıimaktadır

Kubler-Ross, hastaların geçrodiklen bu aşamalan. alelermm ve tedavi ekibu uyelerinn de hastayla ayn şoddetle olmamakla birlikte yaşadıkların tlen surmektedir (Kubler-Ross 1975)

Kubler-Ross'un yukarıda kısaca ozetlenmøye 
çalışılan yaklaşımı, tanımlanan aşamaların olüm sürecinde yaşananları yeterınce açıklayamadığı, "aşama" sózcūğünün teknık bır terim olduğu ve her hastanın geçeceğı herbır aşamayı açıklayabilmesi gerektiği, ancak bu ơlçülerı karşılayamadığı ve süreçte yaşanan anksıyete üzerinde de yeterince durulmadığ vb. nedenlerle eleştirilmektedir (Taylor 1991, s.416). Ancak ne denli eksiklikleri olursa olsun Kübler-Ross'un uzun süren klinik deneyimle- rine dayanarak tanımıadığı bu yaklaşımın alanda çalışanlar için onemli bir rehber olduğu yadsınamaz. Kuşkusuz, bir hastanın emosyonel tepkilerıni anlayabilmenin yararlı bir yolu, hangi duygunun, en çok ne zaman ortaya çıktığ ve bunlarda hangi etkenlerin rol oynadığı ve bunların hastalığın iyileştirilmesinde amaclanan hedefiere ve tedavi manipuJasyonlarına nasıl yardımcı olacağını incelemektir. Ancak boyle bir yaklaşımla uygun psikolojik müdanaleler geliştirilebilhr.

\section{KAYNAKLAR}

Erhat A (1978) Mitolojı Sozluğtu, Remzı Kıtabevı

Kubler-Ross E (1969) On Death and Dying New York, Mac Millan

Kubler Ross E (1975) Sorular ve Cevaplarla Yaşamın Son Gunlen, Inglizceden Çevin G Terakye (ed) Ankara (1992), Hurbitek Matbaacilik

Lazarus RS, Launer R (1978) Stress-reiated Transactions Between Person and Environment In LA Pervin and $M$ Lewis (eds) Intemational and Extemal Determinants of Behavior NewYork, Plenum

Selignan MEP (1975) Helplessness. On Depression, Development and Death San Francisco, Freeman
Tayior SE (1986) Health Psychology. New York Mc Graw-Hill

Taylor SE (1991) Health Psychology New York, Mc Graw-Hill

Volkan V (1985) Psychotherapy of Complicated Mourning In Volkan $V$ (ed), Depressive State and Their Treatment Nortval, Jason Aronson Inc

Volkan V (1993) Life After Loss New York, Charles Scribner's Sons Inc Books

Yalom I (1980) Exıstental Therapy New York, Basic

Yalom I (1989) Love's Executioner New York, Basic Books 